\title{
Robótica pedagógica livre: sobre inclusão sócio-digital e democratização do conhecimento
}

\author{
Daniel Mill* \\ Danilo César**
}

\section{Resumo:}

Neste trabalho, propomos o desenvolvimento de um ambiente educacional dinâmico baseado no uso da robótica como tecnologia de aprendizagem disciplinar. Este texto explora a relação entre softwares livres, sucatas e educação, buscando articular propostas de softwares livres com o processo de construção do conhecimento e com princípios de inclusão social. Desenvolver atividades pedagógicas a partir de sucatas e da abertura do código-fonte de programas de computador constituiu uma rica possibilidade de "democratização" do acesso aos bens culturais e tecnológicos, bem do como ao conhecimento.

Palavras-chave: Robótica. Tecnologia educacional. Inclusão digital. Software livre.

* Doutor em Educação pela Universidade Federal de Minas Gerais (UFMG). Professor e Coordenador de EaD - Universidade Federal de São Carlos (UAB - UFSCar).

**Doutor em Educação pela Universidade Federal da Bahia. Coordenador do Projeto Robótica Livre Escola Municipal Caio Líbano Soares. Analista da Empresa de Informática e Informação do Município de Belo Horizonte (PRODABEL). Minas Gerais. 


\section{Considerações preliminares}

Neste trabalho, fazemos um convite ao leitor a refletir conosco sobre um tema duplamente interessante: a robótica pedagógica livre. Para além da simples discussão sobre tecnologia educacional, apresentamos uma proposta de robótica pedagógica, isto é, propomos o desenvolvimento de um ambiente educacional dinâmico baseado no uso da robótica como tecnologia de aprendizagem transdisciplinar. Discutimos alguns aspectos relacionados aos princípios psicopedagógicos desse ambiente, inclusive sobre o enorme poder de sedução ou fascínio que a robótica ou os robôs exercem sobre o ser humano, principalmente sobre gerações mais jovens.

Além de ser um tema que desperta em muito o interesse de jovens em formação, o foco da discussão deste trabalho abrange um segundo aspecto. O ambiente educacional aqui apresentado é sócio-economicamente e politicamente correto, pois faz uso de tecnologias livres. Em outras palavras, agregamos à reflexão deste artigo a proposta de liberdade do Licença Pública Geral (GNU/GPL), ${ }^{1}$ o que pode tornar a robótica pedagógica ainda mais fascinante aos olhos de jovens educandos.

Portanto, sugerimos uma discussão sobre o que é a robótica pedagógica, o software livre, a robótica pedagógica livre, bem como sobre as implicações político-econômicas e sócio-pedagógicas daí decorrentes. Em resumo, o objetivo deste tex to é relacionar e explorar a proposta de softwares livres com o processo de conhecimento e de inclusão social, analisando as possibilidades de uso de sucatas como matéria-prima ou tecnologias de aprendizagem. Quais relações podem ser estabelecidas entre softwares livres, sucatas e educação? Isto é um convite às possibilidades...

\section{Contexto e reflexão}

\section{Entre o robótico e o pedagógico}

Podendo ser considerada como os sistemas que interagem com o mundo real com ou sem intervenção dos humanos, a robótica pertence ao grupo das ciências informáticas e é considerada multidisciplinar, pois agrupa e aplica conhecimentos de microeletrônica (peças eletrônicas do robô), engenharia mecânica (projeto de peças mecânicas do robô), física cinemática 
(movimento do robô), matemática (operações quantitativas), inteligência artificial, dentre outras ciências. Além desses conhecimentos que compõem o desenvolvimento de atividades com a robótica, outras áreas das ciências humanas, por exemplo, podem ser tangenciadas. Questões éticas, morais, culturais, socioeconômicas e humanas, por exemplo, são retomadas sempre que a robótica é colocada como centro das discussões. Especialmente quando relacionadas às questões de dominação, poder e subordinação, acreditamos que seja sensato o receio de alguns grupos sociais em relação aos avanços da inteligência artificial e da robótica.

Entretanto, as aplicações da robótica se multiplicam com grande rapidez cada vez que aparecem novos modelos de computadores e outros dispositivos como sensores, motores, ligas especiais de metal, de carbono etc. São inúmeros os benefícios proporcionados pela presença de mecanismos robóticos em algumas áreas de atuação humana.

A palavra robô é proveniente da palavra Tcheca “robotnik., que significa trabalho árduo ou trabalho escravo (que também pode ser traduzido como sendo operário). Esta concepção justifica os usos que o homem tem feito desse trabalho robótico ou escravo. O trabalho robótico é requisitado, por exemplo, em espaços onde a insalubridade é alta: robôs podem tolerar elevadas ou baixíssimas temperaturas, insuportáveis ao homem.

Desde o início, o desenvolvimento da robótica foi pensado em função do homem. Em geral, as tecnologias são desenvolvidas pelos benefícios que podem proporcionar à humanidade. Os dispositivos robóticos, em especial, não apenas respeitam a esse princípio como também consideram as três precisas e lendárias leis da robótica (mais tarde ampliadas para quatro), apresentadas nos contos de Isaac Asimov, ${ }^{2}$ quais sejam: Lei Zero: Um robô não pode causar mal à humanidade ou, por omissão, permitir que a humanidade sofra algum mal, nem permitir que ela própria o faça;

- Lei 1: Um robô não pode ferir um ser humano ou, por omissão, permitir que um ser humano sofra algum mal;

- Lei 2: Um robô deve obedecer às ordens que lhe sejam dadas por seres humanos, exceto nos casos que em tais ordens contrariem a Primeira Lei;

- Lei 3: Um robô deve proteger sua própria existência, desde que tal proteção não entre em conflito com a Primeira e a Segunda Leis. 
Em filmes de ficção científica como Eu, robô (2004) e A.I.: inteligência artificial (2001) pode ser observada ampla preocupação em respeitar essas leis. Há aí certo receio em relação às consequências que o desenvolvimento da robótica pode trazer ao ser humano - a preocupação, em resumo, reside no peso dado aos benefícios e malefícios que essas criações podem representar. Apesar de alguns exageros por vezes percebidos, toda essa preocupação procede, mas pedagogicamente falando essa perspectiva de análise restringe-se ao que D’Abreu (1999) chamou de enfoque tradicional, por estar centrado na utilização de robôs com características puramente técnico-industriais. Nesta perspectiva, a robótica é definida como o conjunto de conceitos básicos de mecânica, cinemática, automação, hidráulica, informática e inteligência artificial, envolvidos no funcionamento de um robô (USATEGUI; LEON, 1986). Nesse caso, a robótica consiste no desenvolvimento de máquinas e dispositivos autômatos (denominados robôs) que possam executar tarefas independentes do manuseio humano, seguindo uma programação previamente estabelecida.

Entretanto, relembrando que concebemos como robôs não somente criações à imagem e semelhança dos homens, neste trabalho queremos explorar um aspecto que extrapola a fobia humana em relação ao "brincar de Deus" dos cientistas. Para além da hipótese levantada por John Cohen (BRETON, 1995, p. 11) - em que os robôs humanos corresponderiam ao desejo do homem de se afirmar como criador à semelhança de um Deus - queremos destacar a relação entre a criação robótica naquela perspectiva industrial e a pedagogia. Em outras palavras, enfocaremos o uso da robótica industrial num contexto em que as atividades de construção e controle de dispositivos propiciem o manuseio de conceitos de ciências em geral num ambiente de sala de aula, nos diferentes níveis de ensino. Esta perspectiva de análise é chamada por D’Abreu (1999) como pedagógico-educacional, em que a ideia central é propiciar ambientes de aprendizagem baseados em dispositivos robóticos que permitem a construção do conhecimento nas diferentes áreas das ciências. Há, portanto, nestas propostas de robótica pedagógica, um intencional esforço para a construção dos robôs para serem usados como oportunidade para a aprendizagem do aluno.

Aqui a preocupação da proposta pedagógica com o uso de dispositivos robóticos enfoca, como argumenta Lion (1997, p. 23), os processos e não os produtos. Esta autora apresenta a supremacia do valor dos produtos 
acima dos processos como um mito. Acredita-se que esse mito se cristaliza com a modernidade e que se plasma na separação entre tecnologia e técnica. Compreendem-se nessa discussão não apenas as matérias-primas, as ferramentas, as máquinas e os produtos, como também o produtor. As atividades de elaboração, construção de dispositivos, programação, testes e avaliações constituem-se, então, na chave para a aquisição de competências por parte das pessoas envolvidas. Antes, importam aqui as pessoas. Nesse caso, cabem perguntas do tipo: de que forma o desenvolvimento de artefatos robóticos pode beneficiar a construção do conhecimento? Que análise pode ser feita entre robótica e democratização do conhecimento?

Considerando o posicionamento de Dowbor (2004, p. 24), "as novas tecnologias são um instrumento à espera do tipo de utilização que dele fazemos", pode-se observar um benefício indireto da robótica: o seu uso no ensino-aprendizagem. Para além da benevolência ou maleficência das tecnologias robóticas, acreditamos que tratam-se de tecnologias ou artefatos operários capazes de auxiliar na construção do conhecimento.

\section{Sobre a robótica pedagógica}

A tentativa de uso da robótica na construção de metodologias pedagógicas não é nenhuma novidade nem tampouco nenhum bicho de sete cabeças. Comprovadamente, esta parte da ciência que se dedica a estudar os robôs, os autômatos, tem muito a contribuir para o processo pedagógico de construção do conhecimento. Numa primeira análise, é perceptível que a proposta de robótica pedagógica está em consonância com os princípios do construtivismo. Educadores e pensadores como Seymour Papert buscam, desde há muito, essa conciliação entre dispositivos mecânicos e eletrônicos e o processo de ensino-aprendizagem. A construção de um ambiente em que educadores e educandos desenvolvam sua criatividade, seu conhecimento, sua inteligência, seu potencial em lidar com situações adversas do cotidiano tem sido um dos principais motivadores para as tentativas de integração da robótica nas práticas educacionais.

Características como a transdisciplinaridade e a motivação humana pela criação de robôs tornam a robótica uma interessante ferramenta de uso na educação. Projetos com robótica pedagógica oportunizam situações de aprendizagem pela resolução de problemas inter ou transdisciplinares, 
que podem ser mais simples ou mais complexos, dependendo do nível de ensino em que for aplicado (e vale lembrar aqui que um mesmo projeto de robótica pedagógica pode envolver diferentes graus de complexidade e atender a propostas pedagógicas para o ensino fundamental, médio ou superior).

Educadores que empregam esses instrumentos robóticos na educação denominam esse processo de robótica pedagógica ou robótica educacional. Mas o que pode ser concebido como robótica pedagógica? Existe aí algum equívoco conceitual?

Ainda que não chegue a constituir um equívoco, ao menos entre os educadores que aplicam a robótica como metodologia pedagógica é facilmente perceptível uma certa confusão em torno da definição de robótica pedagógica. O mesmo ocorre em páginas de Internet que tratam do assunto. Ora encontramos o termo robótica pedagógica relacionado aos dispositivos robóticos, às máquinas (ao hardware); ora relaciona-se ao espaço físico, ao laboratório ou ao ambiente de aprendizagem; e, por vezes, o termo aparece como sinônimo do projeto em desenvolvimento ou mesmo como a metodologia em si... o fato é que parece não haver um consenso ou preocupação em definir o que possa ser considerado como robótica pedagógica.

Sem a ambição de conceber um conceito acertado ou acabado, faremos uso da expressão robótica pedagógica como proposta pedagógica; isto é, consideramos que robótica pedagógica é uma denominação para o conjunto de processos e procedimentos envolvidos em propostas de ensino-aprendizagem que tomam os dispositivos robóticos como tecnologia de mediação para a construção do conhecimento. Desta forma, quando nos referirmos à robótica pedagógica não estaremos falando da tecnologia ou dos artefatos robóticos em si, nem do ambiente físico onde as atividades são desenvolvidas. Não estaremos nos referindo a outra coisa senão à proposta de possibilidades metodológicas de uso de tecnologias informáticas e robóticas no processo de ensino-aprendizagem.

Do mesmo modo, por robótica pedagógica alternativa compreendemos o conjunto de processos e procedimentos envolvidos em propostas de ensino-aprendizagem que tomam os dispositivos robóticos baseados em soluções livres e em sucatas como tecnologia de mediação para a construção do conhecimento. De forma específica, trataremos a Robótica Pedagógica Alternativa como Robótica Livre, denominação utilizada pelo grupo 
de educadores e educandos envolvidos na experiência de robótica que apresentaremos neste texto.

\section{Sobre software livre}

O desenvolvimento do que conhecemos hoje como GNU/Linux deve-se, em boa parte a dois pesquisadores: Richard Stallman e Linus Torvalds. Segundo Zilli (2005), em 1983, o então pesquisador-programador do Instituto de Tecnologia de Massachusetts (MIT), Richard Stallman, formalizou o conceito de Software Livre em um manifesto no qual apresentava e discutia a definição e a versão inicial da licença de uso de um programa livre: a licença GNU, também conhecida como Licença Pública Geral (GPL). Esta iniciativa ocorreu ao ver o resultado de um trabalho acadêmico ser vendido a uma empresa e, com isso, ser trancafiado para sempre atrás de contratos de licença impenetráveis. Para defender seus ideais, Stallman fundou a Free Software Foundation (FSF), que defende o conceito de Software Livre. O objetivo do projeto é criar um sistema operacional e aplicativos livres para as pessoas usarem. O outro pesquisador importante da área é Linus Torvalds, que em 1991, criou o núcleo do sistema operacional Linux e o distribuiu com código-fonte aberto para que outros interessados pudessem fazer uso ou implementar melhorias na sua estrutura e redistribuir. Por deixar o código-fonte aberto, o software livre abre a chance de que todo usuário se torne também um desenvolvedor do programa, compartilhando suas soluções com outros usuários (A TRAMA..., 2005, p. 15). Em torno dessa ideia, cria-se, em pouco tempo, uma poderosa inteligência coletiva... surge então a Comunidade Linux.

De 1985 para cá, o projeto criou compiladores, bibliotecas, editores de texto e centenas de outros programas. Além disso, hoje a FSF trabalha também no campo social incentivando e atuando na inclusão digital em vários países.

Em que consiste, afinal e verdadeiramente, o Software Livre?

"Software Livre" é uma questão de liberdade, não de preço. Para entender o conceito, você deve pensar em "liberdade de expressão", não em “cerveja grátis.” (O QUE..., 2005).

Por isso, afirma-se que software livre não é o mesmo que software gratuito. Este último tem como característica central o não-pagamento pelas 
licenças de uso e a manutenção do código-fonte fechado ou oculto. Isso fere por completo os princípios da Comunidade Livre. Pode ser observado em GNU.ORG (O QUE... 2005) que Software Livre se refere: à liberdade dos usuários executarem, copiarem, distribuírem, estudarem, modificarem e aperfeiçoarem o software. Mais precisamente, ele se refere a quatro tipos de liberdade, para os usuários do software:

- Liberdade 0: liberdade de executar o programa, para qualquer propósito;

- Liberdade 1: liberdade de estudar como o programa funciona, e adaptá-lo para as suas necessidades;

- Liberdade 2: liberdade de redistribuir cópias de modo que você possa ajudar ao seu próximo;

- Liberdade 3: a liberdade de aperfeiçoar o programa, e liberar os seus aperfeiçoamentos, de modo que toda a comunidade se beneficie.

Enfim, um programa de computador é software livre se os usuários têm todas essas liberdades, de forma irrevogável. Desta forma, merece destacar a importância do acesso ao código-fonte como condição necessária para que o software possa ser considerado livre. Acesso ao código-fonte é um pré-requisito para o estabelecimento das liberdades, especialmente das liberdades de número um e três. O que é código-fonte?

Código-fonte são as rotinas que o hardware deve seguir, escritas em uma determinada linguagem. É como se fosse a receita do bolo que você está comendo. Sem acesso ao código-fonte de um software, não sabemos se ele faz exatamente o que ele diz fazer. (A TRAMA, 2005, p. 14).

É nessa perspectiva, associada aos princípios do copyleft, ${ }^{3}$ que apresentamos a proposta de Robótica Livre. Além de explorar as potencialidades da robótica pedagógica, acreditamos também nesse viés do acesso à receita do bolo... ou seja, acreditamos que, ao acessar o processo de produção do robô e na elaboração do programa do computador para controle dos dispositivos robóticos, os educandos e educadores estarão diante de uma poderosa estratégia de produção de conhecimento. Voltaremos a discutir esse aspecto ao final do texto. 


\section{Projeto Robótica pedagógica livre: o alternativo sob análise}

Existem, atualmente, diversas experiências pedagógicas pelo Brasil envolvendo robótica pedagógica. Entretanto, a maioria delas faz uso de materiais comercialmente distribuídos: kits com módulos pré-confeccionados (Lego, por exemplo) e softwares de controle e acionamento de dispositivos eletromecânicos (como o LOGO e similares). Como exemplo de robótica pedagógica com materiais distribuídos comercialmente, Guimarães (2004) relata o caso da Escola Municipal Osvaldo Arnes, localizada em Curitiba-PR.

Todas essas experiências proporcionam resultados extremamente interessantes e positivos. Entretanto, não se enquadram na perspectiva de análise deste texto. As reflexões aqui propostas serão feitas a partir de uma experiência de robótica pedagógica alternativa, implementada numa escola da Rede Municipal de Ensino de Belo Horizonte, desde 2004. O Projeto Robótica Livre - como é chamado pelos envolvidos na experiência - tem uma proposta diferenciada, o que lhe rendeu segundo lugar no concurso do Prêmio Telemar de Inclusão Digital. A seguir, apresentamos a proposta com um pouco mais de detalhes e, após, faremos uma análise crítica com vistas ao atendimento do propósito deste texto.

\section{Sobre o projeto de robótica livre}

O Projeto robótica livre ainda está em fase de implementação, na Escola Municipal Caio Líbano Soares em Belo Horizonte - Minas Gerais, que possui um laboratório de informática totalmente montado com software livre desde julho de 2001. Portanto, desde essa ocasião, todos os professores e alunos desta escola já desenvolvem atividades com software livre ou, ao menos, mantém algum contato - direto ou indireto - com esse tipo de software.

O trabalho enfoca a implementação de um ambiente dinâmico de robótica pedagógica com soluções tecnológicas livres e está em funcionamento efetivo desde início de 2004. Nesta fase inicial, o projeto contou com a participação de 16 pessoas (professores e alunos) envolvidas na educação de jovens e adultos (EJA) ${ }^{4}$ da Escola Municipal Caio Libano Soares.

Ainda que esta proposta se estruture e se estenda para muito além dos softwares dos quais faz uso, ela inspirou-se integralmente na licença 
GNU - GPL (Licença Pública Geral). Eis aí boa parte do seu diferencial: enquanto a maioria dos projetos de robótica pedagógica é desenvolvida com a utilização de kits padronizados, o Projeto Robótica Livre parte para soluções livres em substituição aos produtos comerciais. Propõe-se o uso de softwares livres (Linux ${ }^{5}$ e seus aplicativos) como base para a programação e a utilização de sucata de equipamentos eletroeletrônicos como material para a construção de robôs. Apesar de buscar um modelo de ambiente com soluções livres, utilizando recursos tecnológicos já existentes, o grupo envolvido com o Projeto Robótica Livre da Escola Municipal Caio Líbano Soares busca também a apropriação de conceitos de produção e desenvolvimento de produtos próprios.

Nesta perspectiva, foi estabelecido como objetivo geral do Projeto Robótica Livre a construção de um ambiente dinâmico de aprendizagem através de um projeto de robótica que faça uso exclusivamente de soluções de software livre e que tenha sucata de equipamentos eletroeletrônicos como principal material de construção de seus produtos.

Para caracterizar bem o projeto, podemos resumir seus objetivos específicos em uma proposta que busca desenvolver uma metodologia de trabalho cooperativa capaz de possibilitar ao grupo envolvido: aprender de forma autônoma, ainda que orientada; utilizar soluções de controle informatizado de dispositivos eletromecânicos e eletrônicos baseadas exclusivamente em software livre; reaproveitar componentes eletromecânicos e eletrônicos de máquinas e equipamentos em desuso como base para construção de dispositivos de robótica; participação na apresentação da proposta, na formação dos grupos e na organização das atividades.

Como justificativa do Projeto Robótica Livre, foi estabelecida uma contraposição entre ele e a robótica pedagógica com soluções proprietárias. De um modo geral, a chamada Robótica Educacional se desenvolve no ambiente escolar com o uso de modelos padronizados, produzidos e comercializados como pequenos kits. Essas soluções, ainda que permitam aos alunos aprender os conceitos e construir com criatividade seus dispositivos autônomos, implicam em uma excessiva formatação, restringindo as possibilidades de construção à manipulação das peças e módulos de encaixe pré-fabricados. 
Além disso, os preços dos produtos (hardware) comerciais inibem o desenvolvimento de projetos de robótica pedagógica, pois normalmente superam a capacidade de investimento da maioria das escolas, em particular das escolas públicas brasileiras. Também o uso de programas de computador proprietários (softwares), de custo significativo e que, principalmente, não dá ao usuário o direito de manipular sua estrutura, restringe as possibilidades de uma prática pedagógica adequada e de baixo custo.

Em contraposição a esses fatores, o Projeto Robótica Livre parte para soluções livres (copyleft) em substituição a esses produtos comerciais. Assim, propõe o uso de softwares livres (plataforma LINUX e seus aplicativos) como base para programação e a utilização de sucata de equipamentos eletroeletrônicos como material para construção de robôs. O uso de soluções livres e de componentes de equipamentos eletromecânicos e eletrônicos fora de uso (sucata) garante a possibilidade de manipulação em um nível mais estrutural e uma diminuição drástica nos custos do projeto.

O projeto se desenvolve em torno de oficinas de construção de soluções de robótica. Cada um dos encontros para as oficinas têm duração de 90 minutos e ocorrem semanalmente. Todos os encontros, inclusive aqueles destinados às discussões dos fundamentos teóricos, são desenvolvidos com o auxilio do computador e dos dispositivos robóticos, utilizando-se de material em formato digital disponível na Internet, por exemplo. A iniciativa de ter uma página de Internet (www.emcls.pbh.gov.br/robotica) para registrar os relatos das experiências e dos produtos desenvolvidos no grupo teve como pano-de-fundo a maior integração dos artefatos informáticos ao processo pedagógico decorrente do Projeto Robótica Livre.

Vale registrar que, além do grupo envolvido no Projeto Robótica Livre, alguns professores (inclusive o coordenador do programa LabFUST ${ }^{\sigma}$ ) oferecem apoio voluntário. Isso dá maior visibilidade à interface entre o projeto e a escola, possibilitando o atendimento a alguma demanda específica do Projeto Robótica Livre.

Enfim, acredita-se que a dinâmica do Projeto esteja sendo interessante, pois tem produzido um ambiente dinâmico de aprendizagem, com interação cooperativa e solidária. Nesse sentido, percebe-se uma formação indireta e diferenciada para o docente, que vivencia uma nova forma para as práticas pedagógicas em que ele se aproxima dos alunos como colegas de projeto. Comumente, o aluno se coloca como "par mais capaz" na relação entre 
eles. Como consequência da dinâmica do ambiente, o aluno se percebe mais atuante, com elevação da auto-estima e confiança em suas capacidades.

Uma oportunidade impar e, portanto, marcante do projeto demonstra esse alto potencial do Projeto Robótica Livre, inclusive como meio de politização dos participantes foi a experiência de participação na XX Inforuso Sucesu 2004 - Vigésima Feira de Informática e Tecnologia de Minas Gerais. Recentemente, foi realizado um torneio de robótica como parte dos eventos propostos para a INFORUSO. Nesse torneio, apresentam-se equipes com projetos já estabilizados, com alunos experientes e que, geralmente, têm nível universitário. Naquela oportunidade, o Projeto Robótica Livre da Escola Municipal Caio Líbano Soares estava ainda no começo, na etapa de formação dos grupos e de discussão dos conceitos e das propostas de trabalho. Convidada para participar do torneio, a escola encaminhou ao evento um grupo de seis alunos que, sem participar das disputas, apresentaram a proposta do Projeto Robótica Livre aos visitantes da feira e aos participantes da disputa entre robôs, defendendo a pertinência de um projeto de "hardware livre", baseado no aproveitamento de sucata e no uso do "software livre", em um ambiente em que, de modo geral, usam-se soluções proprietárias caras e padronizadas. Os alunos, ainda sem desenvoltura traduzida na construção dos produtos, mostraram muita competência na defesa de aspectos pedagógicos, financeiros e socioculturais que diferenciam o projeto.

Também a publicação do conhecimento produzido em informações detalhadas abertas aos interessados demonstra a assimilação dos conceitos de "copyleft" presentes na comunidade de software livre e que sustentam a disseminação da produção intelectual sem reservas de direitos autorais ou patentes.

A análise de custos do projeto, envolvendo a aquisição e manutenção dos equipamentos e softwares utilizados mostra uma situação muito favorável ao projeto, chegando a menos de $10 \%$ de uma solução proprietária comercializada no mercado.

Frente aos resultados atingidos pelo Projeto Robótica Livre, objetiva-se a criação de novos grupos na E.M. Caio Líbano Soares, sob a responsabilidade das pessoas que hoje participam da primeira turma. Há também a pretensão de expandir o projeto para outras escolas da Rede 
Municipal de Educação de Belo Horizonte e, quiçá, para outras instituições que se interessarem pela proposta.

Finalmente, em respeito ao protocolo GNU, pretende-se promover a publicidade do Projeto, de seus objetivos e da metodologia desenvolvida, propondo sua livre apropriação pelos que se interessarem. Ou seja, pretendese a promoção do desenvolvimento cooperativo dessa metodologia pela comunidade de usuários a se constituída.

\section{Sobre o código-fonte da robótica pedagógica livre}

Como linguagem de programação para controle dos dispositivos eletrônicos podem ser utilizadas a SuperLogo, Shell Script, $\mathrm{C}++$, java etc. Seguindo o princípio do software livre, apresentamos no Quadro 1 o código-fonte do programa para controle de dispositivos robóticos do Projeto Robótica Livre, como utilizado para produção deste trabalho.

\section{Robótica pedagógica: contribuições para o debate}

Durante o desenvolvimento do Projeto Robótica Livre, foi observado que os educandos aprendem com o desafio de dominar os recursos da robótica para construir seu próprio projeto, conseguindo inclusive verbalizar a articulação de diversos conteúdos da matemática, química, física, biologia, sociologia, história e geografia, entre outras áreas. A participação ativa do educando na construção e controle de seus objetos de desejo, agregando conteúdos escolares com práticas reais/concretas, faz com que o mesmo se sinta parte do processo e do meio em que vive, ampliando seus conhecimentos através da mensagem transmitida pelo professor ou outro membro do grupo. Esta prática parece coerente com os princípios construtivistas de Piaget sobre o desenvolvimento cognitivo, os quais foram revisados para o construcionismo por Seymour Papert (1985).

Aspectos ecológicos e de liberdade/compartilhamento também sempre estiveram na pauta das preocupações dos envolvidos no Projeto Robótica Livre. Por um lado, praticava-se uma postura mais ecológica a partir da reutilização de materiais descartados, quando todos foram percebendo que elementos/componentes tidos como lixo podem ser fonte de recursos nos processos de desenvolvimento de novos produtos. Do mesmo modo 
e por outro lado, a compreensão e a prática dos conceitos de copyleft e software livre levou os participantes do Projeto a perceberem a importância do compartilhamento de trabalho, da informação e do conhecimento para a inteligência coletiva do grupo.

Foi interessante observar, também, o esforço do grupo para desmistificar a falácia de que soluções de baixo custo são soluções de baixa qualidade ou inviáveis. Enfim, ousamos afirmar que os resultados alcançados são satisfatórios. Um bom termômetro para comprovar isso é o fato de que, a cada etapa concluída, os educandos se mostraram ainda mais motivados com o projeto. Outro indicador satisfatório é que os educandos demonstraram domínio de competências e habilidades propostas, relacionadas tanto ao conteúdo específico da robótica quanto às dinâmicas de ensino-aprendizagem que direcionam o projeto.

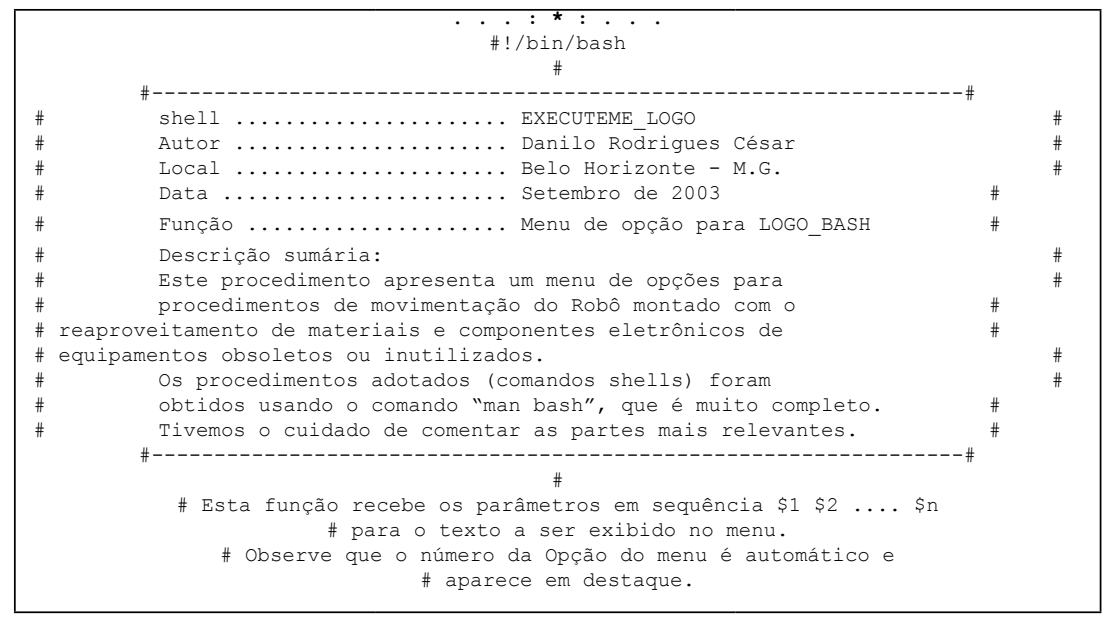

continua 
continuação de

\begin{tabular}{|c|c|c|}
\hline 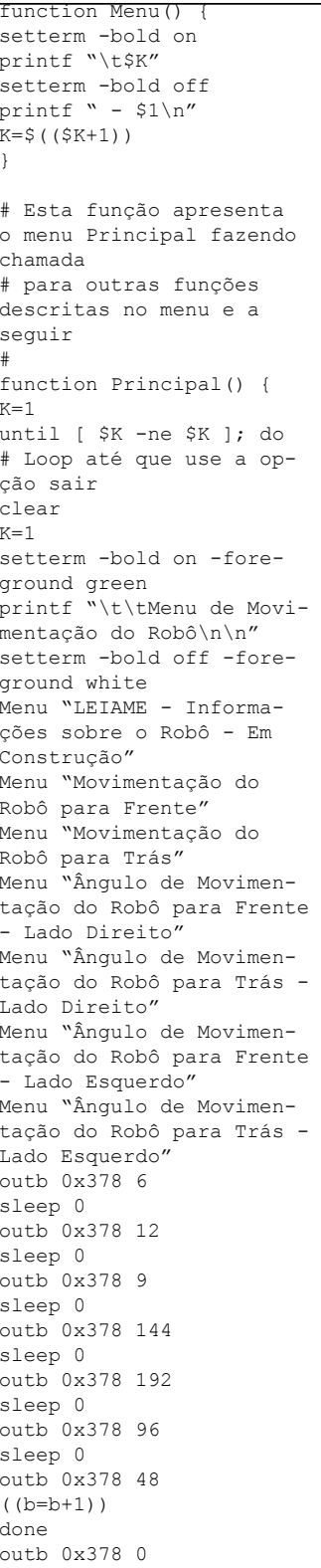 & 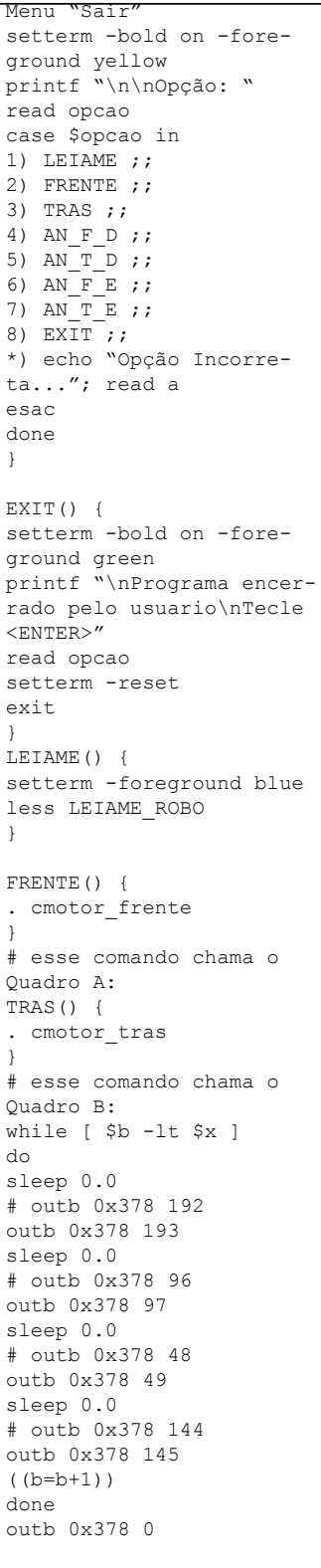 & 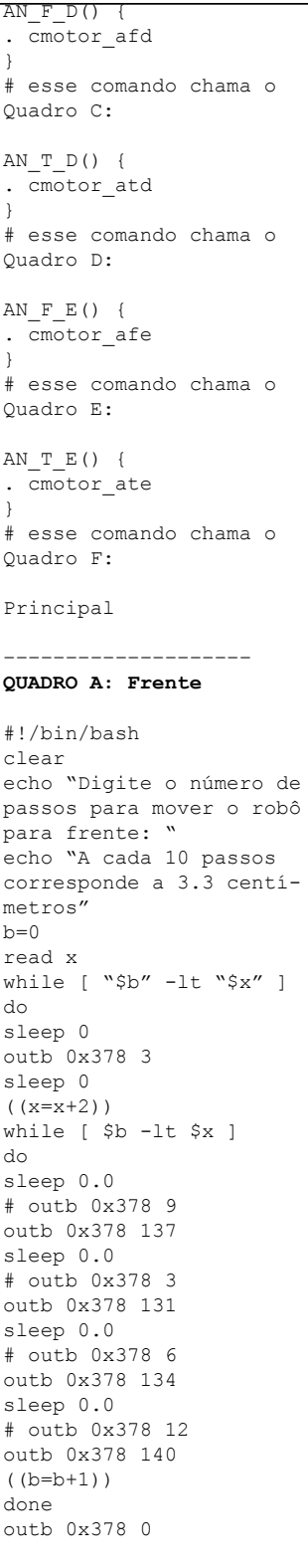 \\
\hline
\end{tabular}


continuação de

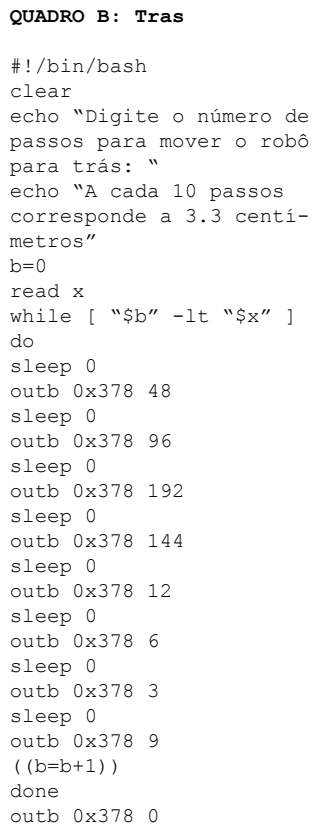

Quadro 1 - Código-fonte do programa para controle de dispositivos robóticos do Projeto Robótica Livre

Fonte: Desenvolvido e sistematizado pelos autores deste texto.
QUADRO F: Ate

\#! /bin/bash

clear

echo "Digite o ângulo para

mover o robô para trás

(lado esquerdo): "

$\mathrm{b}=0$

read $\mathrm{x}$

while [ \$x -gt 360 ]

do

echo "Digite um ângulo

inteiro menor ou igual a

$360 "$

read $\mathrm{x}$

done

$((x=x+2))$

while [ $\$ b-1 t \$ x]$

do

sleep 0.0

\# outb $0 \times 378 \quad 12$

outb $0 \times 378140$

sleep 0.0

\# outb $0 \times 3786$

outb $0 \times 378 \quad 134$

sleep 0.0

\# outb $0 \times 378 \quad 3$

outb $0 \times 378131$

sleep 0.0

\# outb $0 \times 3789$

outb $0 \times 378 \quad 137$

$((\mathrm{b}=\mathrm{b}+1))$

done

outb $0 \times 3780$

\section{QUADRO E: Afe}

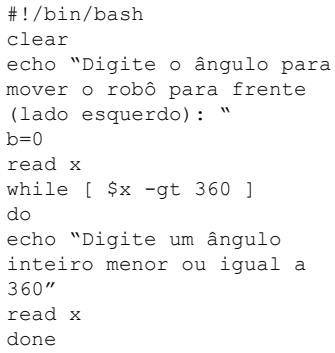


$\mathrm{Na}$ fase inicial do projeto não foi formalizada ou prevista nenhuma atividade para formação ética, ecológica ou política. Entretanto, ainda assim, a consolidação de alguns saberes relacionados a essas áreas podia ser, recorrentemente, percebida em conversas informais ou durante outras atividades. Certamente, essas e outras áreas (alternativas) do conhecimento serão trabalhadas mais sistematicamente, em fases futuras do Projeto Robótica Livre. Esses aspectos ético-políticos e ecológicos vêm à tona como diferenciais da robótica pedagógica alternativa em relação à robótica pedagógica baseada em materiais e softwares distribuídos comercialmente.

A Robótica Pedagógica não se propõe a uma alfabetização em tecnologia, nem ao aprendizado das técnicas, nem ao conhecimento e orientação para uma educação profissional; ela pretende discutir a educação numa estreita relação com a tecnologia, numa visão contextualizada, tendo por objetivo formar o cidadão para viver o seu tempo - em que a tecnologia está presente não como apêndice, mas como realidade que não pode ser ignorada ou desconhecida - de forma mais humana possível. (PEREIRA, 2008).

Esta mesma análise é ainda mais pertinente quando se trabalha com a idéia do Projeto de Robótica Livre, pois o trabalho com programas de código-fonte aberto e com materiais de sucatas pode ser visto como uma rica possibilidade de "democratização" do acesso aos bens culturais e tecnológicos, assim como ao conhecimento. Acreditamos que esse uso de materiais alternativos e de programas de computador com código aberto destaca o poderoso potencial de resgate da cidadania dos grupos socioeconomicamente desfavorecidos. Em seu livro Tecnologias do conhecimento: os desafios da educação, Dowbor (2004) discute o deslocamento dos paradigmas da educação quando afirma que

Não é preciso ser nenhum deslumbrado da eletrônica para constatar que o movimento transformador que atinge hoje a informação, a comunicação e a própria educação constitui uma profunda revolução tecnológica. Este potencial pode ser visto como fator 
de desequilíbrios, reforçando as ilhas de excelência destinadas a grupos privilegiados, ou pode constituir uma poderosa alavanca de promoção e resgate da cidadania de uma grande massa de marginalizados, criando no país uma base ampla de conhecimento, uma autêntica revolução cientifica e cultural. (DOWBOR, 2004, p. 29).

Desta forma, é possível visualizar que o diferencial do Projeto Robótica Livre, em relação aos projetos baseados em kits comerciais préconfeccionados, constitui-se numa poderosa ferramenta de formação para a cidadania e inclusão digital. Discussões sobre liberdade, domínio do código, ecologia e desenvolvimento sustentável, concentração de renda e distribuição do conhecimento são alguns dos aspectos que podem ser trabalhados num projeto de robótica pedagógica livre, ao passo que podem estar praticamente ausentes em projetos pré-montados. Acreditamos que aspectos desta natureza sejam essenciais para a autêntica revolução científica e cultural mencionada acima por Dowbor (2004).

Além disso, na perspectiva pedagógica do construtivismo e do desenvolvimento cognitivo, são muito maiores as possibilidades de trabalho de construção coletiva entre professores e alunos, pois o processo de montagem dos módulos robóticos com sucatas e materiais reaproveitáveis proporciona experiências extremamente ricas para serem exploradas no ensino-aprendizagem. Abrir uma sucata de computador para extrair o que pode ser útil ao projeto traz inúmeras possibilidades de conhecimentos tangenciais ao projeto, além de elevar o poder de abstração do educando ou do educador. A essência do letramento digital e da vida em sociedade (futura) pode estar aí presente.

Em praticamente todas as experiências pedagógicas mediadas por dispositivos robóticos, é facilmente perceptível que propostas dessa natureza conseguem:

- Propiciar a interação, cooperação e aprendizagem coletiva, desenvolvendo assim a consideração e o respeito ao outro. Em projetos de robótica pedagógica, este espírito cooperativo e coletivo está necessariamente presente desde concepção do projeto até o término da experiência; 
- Potencializar formas lúdicas de relacionamento entre o educando e o conhecimento, transformando a aprendizagem em algo divertido e tornando os princípios de ciência e tecnologia mais acessíveis a todos. Esse processo atende aos princípios das propostas construtivista de Piaget e construcionista de Papert;

- Estimular a criatividade e reflexão tanto na concepção das maquetes quanto no processo de programação e criação dos movimentos destas maquetes;

- Desenvolver o raciocínio e a lógica na construção de algoritmos e programas para controle de mecanismos. A elaboração do projeto dos dispositivos robóticos, a montagem da maquete e a criação de movimentos para o robô a partir de um programa de computador exigem um nível de raciocínio lógico-matemático extremamente elaborado e complexo, pois o educando precisa prever milimetricamente os movimentos que deseja que o robô execute, por exemplo;

- Contribuir para o desenvolvimento de aspectos ligados ao planejamento e organização de projetos. Habilidades de gestão do conhecimento, de projetos e de pessoal estão sempre em exercício; especialmente quando a equipe está projetando ou planejando alguma etapa da experiência;

- Possibilitar a vivência do erro como parte do processo. É muito freqüente a ocorrência de erros em projetos de robótica pedagógica: nos cálculos do algoritmo, na montagem da maquete, na previsão dos movimentos do robô etc;

- Preparar os estudantes para passar de simples usuários a criadores de ferramentas tecnológicas. Ao contribuir para o desenvolvimento do projeto, todos os participantes estão vivenciando a criação e isso pode representar uma formação mais cidadã na medida em que o educando participa da produção e aplicação do conhecimento. Em geral, a atuação como simples usuário não pode ser traduzida como democratização do conhecimento;

- Estimular a exploração de aspectos ligados à pesquisa e à ciência. Além de promover a construção de conceitos multidisciplinares - ligados à física, matemática, geografia, história, arquitetura, 
ciências sociais etc. -, as experiências ligadas à robótica pedagógica possuem um enorme potencial de desenvolvimento do espírito científico. Indiretamente, isso pode significar a formação de futuros pesquisadores.

Quando essas experiências pedagógicas são mediadas por dispositivos robóticos alternativos - isto é, montados com sucatas ou materiais reaproveitáveis, fazendo uso de programas de computador com código aberto - podem ser observados não somente esses benefícios relacionados acima, mas também os seguintes:

- Desenvolvimento mais intenso da interação, cooperação, coletividade e do respeito ao outro, pois é exatamente esse o espírito de trabalho da comunidade de Software Livre (Linux);

- Possibilidade de agregar ao projeto preocupações ligadas à proteção da natureza, especialmente em relação à conscientização ecológica e aos recursos não-renováveis;

- Maior estímulo à criatividade e à reflexão quando da coleta das sucatas e montagem dos próprios dispositivos robóticos;

- Criação de oportunidades para politização e conscientização em relação ao desenvolvimento sustentável, à ecologia, à liberdade, ao jogo de poder, à concentração de renda, à produção de softwares proprietários ou com código aberto, ao jogo de poder e à correlação de forças políticas e econômicas em torno do código aberto etc;

- Raciocínio lógico-matemático e poder de abstração mais apurado como resultado da participação na concepção e elaboração do código do programa de computador que comandará os dispositivos robóticos do projeto;

- Participação mais efetiva dos educandos na CRIAÇÃO do projeto a ser desenvolvido, pois não recebem módulos pré-confeccionados por empresas especializadas, além de ser facultada a alteração do código do software de controle do mecanismo robótico - o que significa uma distribuição do conhecimento de forma mais democrática;

- Exploração mais intensa de aspectos ligados à pesquisa e à ciência, especialmente aqueles ligados à ética e à democratização do conhecimento científico. 
Todos esses aspectos foram observados na experiência do Projeto Robótica Livre da Escola Municipal Caio Líbano. Mesmo no processo de planejamento das atividades esses aspectos podem ser pensados e praticados. Diversas atividades transdisciplinares podem ser pensadas para se trabalhar com robótica pedagógica livre. Algumas delas estão sendo discutidas e estudadas pelo grupo do Projeto Robótica Livre para que futuramente sejam montadas:

- Conversão da Base 10 (decimal) para a Base 2 (binária): este projeto irá explorar os conceitos da matemática e informática;

- Elevador: Exploração dos conceitos da física e eletrônica;

- Controle das águas: Projeto explorando os conceitos da geografia e ciências;

- Braço mecânico: Integração de conceitos das ciências físicas e outras;

- Controle de um robô via web: Exploração dos conceitos da informática;

- Controle de um semáforo: Integração dos conceitos da matemática e eletrônica.

Como dito anteriormente e tal como sugerido pelo construtivismo, nestas atividades com robótica pedagógica livre percebe-se o educador intermediando uma aprendizagem e revelando de forma sutil que o saber é algo estruturado mentalmente pelo educando, uma construção conquistada paulatinamente a partir da incorporação de pensamentos, memórias e reflexões, permeada de criatividade. Isto pode ser observado em qualquer atividade educacional com robótica pedagógica.

Tudo isto parece merecer ainda mais crédito por parte dos educadores e governantes quando observamos que essas atividades do Projeto Robótica Livre seguem em consonância com as propostas para o desenvolvimento potencial criativo elaboradas pela Comissão Internacional sobre Educação para o século XXI, coordenada por Jacques Delors e sistematizadas no Relatório para a UNESCO. Num Projeto Robótica Livre podem ser desenvolvidos todos os quatro pilares da educação, propostos por Delors (2001, p. 89): "aprender a conhecer, aprender a fazer, aprender a conviver com outros e aprender a ser" parecem partes constituintes ou peculiares a 
qualquer atividade educacional mediada por tecnologias robóticas de base alternativa (software livre e materiais reaproveitáveis). A robótica livre parece incorporar a nova concepção de educação sugerida por Delors (2001, p. 90): "Uma nova concepção ampliada de educação devia fazer com que todos pudessem descobrir, reanimar e fortalecer o seu potencial criativo - revelar o tesouro escondido em cada um de nós."

Obviamente, numa sociedade marcadamente capitalista, dinâmica e complexa, nem tudo é tão perfeito como parece. Cabem aqui algumas considerações sobre projetos de natureza semelhante aos que utilizam a robótica livre como tecnologia central para o ensino-aprendizagem. Naturalmente, todas essas considerações merecem estudos mais detalhados. O que faremos aqui representa apenas um movimento com o holofote para vislumbrarmos partes por vezes obscuras dessas soluções salvacionistas, por vezes ingênuas. Acreditamos ser imprescindível esta autocrítica para que futuros trabalhos práticos ou teóricos possam cuidar para a superação dos obstáculos reais.

\section{Considerações sobre robótica alternativa}

Quem controla a infra-estrutura controla a rede. Como vimos, esta é uma das propostas básicas do software livre: disponibilizar o códigofonte do programa de computador para que o sujeito da ação passe de mero usuário a criador ou desenvolvedor das tecnologias que utiliza. Esta proposta é imprescindível e louvável. O trabalho com a robótica livre pode realmente proporcionar isto. Entretanto, é preciso cuidar para que a semente seja semeada em terras férteis. Em geral, o usuário comum não compreende em muito as linhas de código disponível. Portanto, acreditamos que deixar o código-fonte disponível pode não bastar para a inclusão digital. Isto ficará mais claro se lembrarmos da problemática que envolve o conceito de inclusão.

Inclusão digital pressupõe, de fato, conhecer tanto o processo (inclusive o código) e o produto (as respostas do software) do trabalho humano. Como defendido por Karl Marx, o princípio da emancipação do sujeito envolve apropriação de todo o processo de produção: desde a concepção até o usufruto do produto. Do contrário, seria muito maior a alienação desse homem. Cabe aqui, porém, analisar certas especificidades 
do trabalho com a informática. Nesse sentido, Machado (1996, p. 14) argumenta que:

É preciso, entretanto, saber distinguir o trabalho do verdadeiro criador, de um lado, e a tarefa do mero funcionário das máquinas, de outro. O funcionário é uma espécie de prótese da máquina (ele é a extensão da máquina e não o contrário), encarregado de ativar os seus mecanismos e pô-la em funcionamento, de modo que ela possa cumprir o programa para o qual foi projetada.

Assim, queremos explicitar aqui que nos parece crucial a preocupação com um segundo passo (para além do "acesso" ao código-fonte); isto é, parece-nos que a luta da Comunidade Livre estará bem mais próxima da vitória quando atingirmos maior inteligibilidade nesses códigos-livres.

"Código versus código. Tecnologias de controle podem ser neutralizadas por tecnologias de liberdade". Esta é a proposta de Manuel Castells para proteção da liberdade de expressão e da privacidade pela Internet. Trata-se de uma tensão entre governos/nações e usuários/ cidadãos.

A questão crítica é a capacidade de conhecer e modificar o código fonte, e aliás todo o software. Num mundo de software de fonte aberta, a capacidade que tem o governo e as corporações de controlar a arquitetura fundamental das aplicações da Internet é vastamente reduzida. O caminho que as sociedades tomarão certamente não depende do próprio código, mas da capacidade que têm as sociedades e suas instituições de impor o código, resistir a ele e modificá-lo. (CASTELLS, 2003, p. 151).

Se a pretensão é criar condições para a utilização plena das "possibilidades da máquina", carece de proporcionar, antes, condições para a formação de criadores em substituição de meros funcionários de máquinas. criar condições para ampliar a capacidade dos "usuários" no sentido de impor o código, resistir a ele e modificá-lo. 
A respeito do letramento digital (e-letramento), defendemos que a capacidade de acesso à tecnologia é pré-condição para inclusão social e digital; ou seja, a capacidade de acesso de cada indivíduo às novas tecnologias (como os códigos-fontes dos softwares livres) depende diretamente do seu nível de alfabetização ou de cognição. Esse é o posicionamento de Santos (2003, p. 10):

O acesso à tecnologia tornou-se tão vital que hoje a inclusão social e a própria sobrevivência passam obrigatoriamente pela capacidade que indivíduos e populações têm de se inserir no mundo das máquinas e de acompanhar as ondas da evolução tecnológica.

Desta forma, merece aqui uma das poucas críticas ao modo ainda incipiente de organização dos sujeitos da comunidade livre. De modo geral, os participantes das comunidades livres tratam as informações nivelando por cima, como se estivessem lidando com um grupo de pessoas já letradas tecnologicamente e profundas conhecedoras do universo de conhecimentos da informática... o que é um grande equívoco. Obviamente, sabemos que existem iniciativas diferenciadas, mas normalmente o conteúdo de ajuda para convidar/seduzir os novos "navegantes" a comporem a comunidade livre não é elaborado de forma muito inteligível para usuários com conhecimento básico ou mediano. Certamente, muitas pessoas desistem e até fazem publicidade contrária quando não se vêem em condições de fazer parte desta comunidade livre... culpa do nivelamento por cima. Elaborar manuais ou instruções com mais cuidado e preocupação pedagógica pode ser uma boa saída. Fica aqui um convite aos pedagogos e aos educadores em geral.

Do contrário, o que estamos discutindo aqui - a inclusão digital - não passará de tentativas de incluir os já incluídos. Quem precisa conquistar a cidadania digital não são aqueles que já possuem todas as pré-condições para fazer bom uso do mundo real. Esses já o conquistaram. O desafio é integrar nessa grande trama da rede informática aqueles excluídos. Não cremos que seja sensato admitir uma nova categoria de excluídos: os excluídos dos incluídos. Em outras palavras, vivemos uma situação em que parece estar havendo um esforço para reintegrar no grupo dos incluídos digitalmente aqueles que já estão incluídos noutras instâncias sociais. Que mérito há em 
trabalhar para ajudar pessoas já alfabetizadas e letradas a compreender uma segunda língua por ser apenas exótica?

Cabe aqui questionar se, em uma sociedade hipercapitalista e multiexcludente, a robótica pedagógica livre está entre os melhores instrumentos para garantir a todos o acesso às tecnologias da informação e combater a exclusão digital?

No livro Software Livre e Inclusão Digital, Silveira e Cassino (2003) propõem a seguinte solução: aderir ao software livre pode contribuir para a inclusão digital e para o combate ao monopólio que existe atualmente sobre os programas de computador. Nesta perspectiva, acreditamos que a robótica pedagógica livre encaixa-se mais que perfeitamente entre as iniciativas imprescindíveis ao combate à exclusão digital. É preciso analisar melhor qual grupo social deve ser incluído; mas, em última instância, trata-se de uma inclusão... ainda que inclusão dos já incluídos (de novo a tal classe dominante).

Afora tudo isso, cabe pensar de fato na inclusão dos excluídos. Nesses tempos em que o Brasil ainda pode ser considerado uma sociedade dos analfabetos funcionais, a já não tão nova e crescente onda de informatização da "vida" humana acabou por produzir uma outra leva de excluídos: os analfabetos digitais. Por vezes ingenuamente, o combate à exclusão digital é um dos principais temas discutidos relacionados à tecnologia de informação.

Silveira e Cassino (2003) acreditam que a barreira econômica ainda é grande e, esbarra, também, no elevado preço dos programas de computador. Assim, propõem o software livre como um caminho para expandir o acesso do brasileiro à Internet, democratizando os meios de comunicação e a própria informação que, desde que o mundo é mundo, é privilégio das classes dominantes. $\mathrm{O}$ grande poder transformador da Internet é justamente possibilitar a democratização na produção, distribuição e acesso a diversos conteúdos. Analisando a situação pelo lado crítico, não podemos deixar de lembrar que falar em democratização do conhecimento requer uma reflexão mais apurada sobre que conhecimentos estão sendo compartilhados. Qual o valor agregado ao conhecimento que é disponibilizado na Internet, por exemplo? 
Por fim, não há como retirar o mérito do Projeto Robótica Livre por estar proporcionando o acesso ao tão disputado código-fonte. Ainda que não tenha implicações imediatas, por ser ainda incipiente, isto trará condições essenciais de formação de criadores e não somente usuários do mundo informático. Traz a possibilidade de intervenção na ordem estabelecida, constituindo numa das principais forças de resistência à mercantilização do conhecimento. Este é o argumento de Bernardo Sorj, ao apresentar os hackers como novos agentes sociais de contravenção:

[Os hackers] desencadearam um movimento contra a apropriação e controle comercial da Internet. A principal contribuição do movimento foi o Open Source Movement (Movimento pela Arquitetura Aberta), que desenvolve softwares com licenças registrados, mas nos quais os códigos-fonte são divulgados. [Este movimento] é a principal força de resistência à mercantilização e ao controle da informação que circula na Internet. (SORJ, 2003, p. 41-42).

Citado por Lion (1997), Michael Apple refere-se à informática, afirmando que:

a nova tecnologia não é unicamente uma montagem de máquinas e seu software. Leva consigo uma forma de pensar técnica que orienta a pessoa [especificamente, o usuário] a ver o mundo de uma maneira particular e que substitui a compreensão política, ética e critica. (LION, 1997, p. 34).

O que há que se fazer talvez seja estimular a "produção" desse sujeito conhecedor do mundo informático e capaz de agir no mundo real. Dessa forma e por outro lado, esse processo de letramento digital (ou mesmo a alfabetização tecnológica) carece de atenção e investimentos por parte dos governantes. Como afirmou recentemente em entrevista Sérgio Amadeu Silveira, um dos defensores do Movimento do Software Livre, a inclusão digital deve se tornar uma política pública, tal como a Educação. O Brasil só conseguiu escolarizar e alfabetizar sua população quando assumiu o seu papel e gastou recursos do fundo público para tal. (...) [Também] é necessário integrar a maioria da população que não está na escola. Por isso, 
a inclusão digital é uma ação de cidadania que envolve as escolas, mas não se restringe a elas.

Como sugerido na introdução deste texto, o que tentamos apresentar aqui foi apenas uma discussão sobre o que é a robótica pedagógica, o software livre, a robótica pedagógica livre, bem como sobre as implicações político-econômicas e sócio-pedagógicas daí decorrentes. Em resumo, o objetivo deste texto é relacionar e explorar a proposta de softwares livres com o processo de conhecimento e de inclusão social/digital, analisando as possibilidades de uso de sucatas como matéria-prima ou tecnologias de aprendizagem.

Tratava-se de um convite às possibilidades... fica agora um apelo: Ai de nós, se por culpa nossa, semente morrer semente!!!

\section{Notas}

1 GNU/General Public License (Licença Pública Geral), GNU/GPL ou simplesmente GPL, é a designação da licença para software livre idealizada por Richard Stallman no final da década de 1980, no âmbito do projeto GNU da Free Software Foundation (FSF). Para saber mais, disponível em: <http://pt.wikipedia.org/wiki/GNU_Gene-ral_Public_License>.

2 Além do livro Eu, Robô, temos também o filme homônimo, dirigido por Alex Proyas e com roteiro baseado na obra de Isaac Asimov (mas não apenas num livro).

3 Copyleft é uma forma de usar a legislação de proteção dos direitos autorais com o objetivo de retirar barreiras à utilização, difusão e modificação de uma obra criativa devido à aplicação clássica das normas de propriedade intelectual, sendo assim diferente do domínio público que não apresenta tais restrições. "Copyleft" é um trocadilho com o termo "copyright" que, traduzido literalmente, significa "direitos de cópia". Richard Stallman popularizou o termo copyleft ao associá-lo em 1988 à licença GPL. Para saber mais, disponível em: < http://pt.wikipedia. org/wiki/Copyleft>.

4 A Educação de Jovens e Adultos (EJA) é uma modalidade específica da Educação Básica que se propõe a atender a um público ao qual foi 
negado o direito à educação durante a infância e/ou adolescência seja pela oferta irregular de vagas, seja pelas inadequações do sistema de ensino ou pelas condições socioeconômicas desfavoráveis. O conceito de EJA muitas vezes confunde-se com o de Ensino Noturno, o que é um equívoco. A EJA define-se muito mais pelas características e especificidades dos sujeitos aos quais ela se destina. Disponível em: $<$ http://www.centrorefeducacional.com.br/eduadult.htm->.

5 Linux é um sistema operacional, programa responsável pelo funcionamento do computador, que faz a comunicação entre hardware (impressora, monitor, mouse, teclado) e software (aplicativos em geral). O conjunto de um kernel e demais programas responsáveis pela comunicação com este é o que denominamos sistema operacional. O kernel é o coração do Linux. Para mais detalhes, disponível em: < http:/ /www. vivaolinux.com.br/linux/ $>$.

6 O LabFUST é uma iniciativa do governo municipal de Belo HorizonteMG, desenvolvida para identificar e avaliar as precondições e os condicionantes que afetam a instalação de laboratórios de acesso à Internet nas escolas de ensino médio do município. Para saber mais, consulte Bemfica (2001, p. 29).

7 Autoria por nós desconhecida, por enquanto.

\section{Referências}

A TRAMA da rede. Folha, São Paulo, n. 32, p.12-16, 22 de fev. de 2005. Sinapse.

A.I.: inteligência artificial. Direção: Steven Spielberg; Roteiro: Brian Aldiss, Ian Watson. Rio de Janeiro: Cine Players, 2001. 1 bobina cinematográfica (146 min.), son., color., $35 \mathrm{~mm}$.

ASIMOV, Isaac. Eu, Robô. Direção de Alex Proyas Roteiro: Isaac Asimov (livro), Jeff Vintar (argumento e roteiro), Akiva Goldsman (roteiro). Rio de Janeiro: Cine Players, 2004. 1 DVD (115min.), son., color. . Eu, robô. Rio de Janeiro: Ediouro, 2004. 
BEMFICA, J. Precondições de uma Democracia Eletrônica - o LabFUST e a universalização do acesso aos serviços de telecomunicações. IP Informática Pública. PRODABEL-PBH, Ano 3, v. 2, 2001, p. 25-43.

BRETON, P. À imagem do homem: do Golem às criaturas virtuais. Lisboa: Instituto Piaget, 1995.

CASTELLS, M. A galáxia da Internet: reflexões sobre a Internet, os negócios e a sociedade. Rio de Janeiro: Jorge Zahar, 2003.

D'ABREU, J. V. V. Desenvolvimento de ambientes de aprendizagem baseados no uso de dispositivos robóticos. SIMPÓSIO BRASILEIRO DE INFORMÁTICA NA EDUCAÇÃO - SBIE99, 11., 1999, Curitiba. Anais... Curitiba, PR: UFPR, 1999.

DELORS, J. Educação: um tesouro a descobrir. São Paulo: Cortez; Brasília: MEC/ UNESCO, 2001.

DOWBOR, L. Tecnologias do conhecimento: os desafios da educação. Petrópolis: Vozes, 2004.

FREITAS, W. Utilização de tecnologia de Groupware no desenvolvimento de recursos humanos: uma análise comparativa entre dinâmicas disjuntas no ambiente de trabalho da Prefeitura de Belo Horizonte. Dissertação (Mestrado em Administração Pública e Tecnologias da Informação)Escola de Governo da Fundação João Pinheiro, Belo Horizonte, 2001.

GUIMARÃES, A. Um brinquedo que é pura tecnologia. Nova Escola. São Paulo, n.171, p. 42-43, abr. 2004.

LION, C. Mitos e realidades na tecnologia educacional. In: LITWIN, E. Tecnologia educacional: políticas, histórias e propostas. Porto Alegre: Artes Médicas, 1997.

MACHADO, A. Máquina e imaginário: o desafio das poéticas das tecnologias. São Paulo: Edusp, 1996.

O QUE é o software livre? In: GNU.org:: philosophy: Free Software Foundation. Boston, EUA, 2005. Disponível em: <http://www.gnu.org/ philosophy/free-sw.pt.html>. Acesso em: 28 fev. 2005.

PAPERT, S. Logo: Computadores e Educação. São Paulo: Editora Brasiliense, 1985. 
PEREIRA, P. H. Robótica Pedagógica: uma aplicação em sala. In: X INTERNATIONAL CONFERENCE ON ENGINEERING AND TECHNOLOGY EDUCATION, 2008, Peruíbe-Santos. Anais... Santos: COPEC, 2008. v. 1, p. 891-895.

SANTOS, L. G. Politizar as novas tecnologias: o impacto sócio-técnico da informação digital e genética. São Paulo: Ed. 34, 2003.

SILVEIRA, S. A.; CASSINO, J. Software livre e inclusão digital. São Paulo: Conrad. 2003.

SORJ, B.Brasi@povo.com: a luta contra a desigualdade na sociedade da informação. Rio de Janeiro: Jorge Zahar; Brasília: Unesco, 2003.

USATEGUI, J. M. A.; LEON, J. N. S. Guia fácil de robótica. Madrid: Paraninfo, 1986.

ZILLI, Daniel. Mundo livre. 4. ed. [s.l.: s.n.], 2005. Disponível em: <http://zilli.gulinuxsul.org/livros/ml.pdf.>. Acesso em: 2 mar. 2005. 


\section{Free pedagogic robotics: socio-digital inclusion and democratization of knowledge}

\begin{abstract}
:
This paper proposes the development of a dynamic educational environment based on the use of robotics as educational technology. This text explores the relationship between free software, discarded computer equipment and education, seeking to articulate proposals for free software with the process of construction of knowledge and with principles of social inclusion. The development of pedagogical activities using discarded equipment and the opening of source code for computer programs constitutes a rich possibility for the "democratization" of access to cultural and technological goods, as well as of knowledge.
\end{abstract}

Key words: Robotics. Educational technology. Digital inclusion. Free software.

\section{Robótica pedagógica libre: sobre inclusión socio-digital y democratización del conocimiento}

\section{Resumen:}

Proponemos en este texto el desarrollo de un ambiente dinámico basado en el uso de la robótica como tecnología de aprendizaje disciplinar. Este trabajo explora la relación de softwares libres, material descartable y educación, buscando articular propuestas de software libres con el proceso de construcción del conocimiento y con el principio de inclusión social. Desarrollar actividades pedagógicas a partir de los materiales descartables y de la abertura del código-fuente de programas de computador constituyó una rica oportunidad de "democratización" del acceso a los bienes culturales y tecnológicos, como también al conocimiento.

Palabras-clave: Robótica.Tecnología educacional. Inclusión digital. Software livre. 


\section{Daniel Mill}

UAB-UFSCar- Coordenação de educação à distância

Rodovia Washington Luís, km 235 - SP-310

São Carlos - São Paulo

CEP: $13.565-905$

E-mail:mill@ufscar.br

\section{Danilo César}

Empresa de Informática e Informação do Município de Belo Horizonte Av. Presidente Carlos Luz 1275 - Caiçara

CEP: 31230-000 - Belo Horizonte, MG

E-mail:danilorcesar@gmail.com

Recebido em: 11/12/2008

Aprovado em: 10/2/2009 